\title{
TEORIA SOCIAL E COMUNICAÇÃO: REPRESENTAÇÕES SOCIAIS, PRODUÇÃO DE SENTIDOS E CONSTRUÇÃO DOS IMAGINÁRIOS MIDIÁTICOS'
}

Valdir José Morigi²

UFRGS

\section{INTRODUÇÃO}

Antes de iniciar a abordar a temática que pretendo desenvolver neste artigo sobre a interação da teoria social com a comunicação alguém certamente poderia objetar, afirmando que a Teoria das Representações Sociais não pertence à teoria social como se conhece tradicionalmente nas Ciências Sociais. A Teoria das Representações Sociais tal como foi desenvolvida por Moscovici (1961) se liga à Psicologia Social. Moscovici atualizou o conceito sobre as representações coletivas elaborado em 1898 por E. Durkheim. O conceito pode não parecer diretamente relacionado com as teorias das Ciências Sociais, como se concebe o pensamento social clássico. Entretanto a sua origem decorre delas, particularmente da Sociologia. O próprio autor reconhece Durkheim como seu antecessor. As noções de representações sociais tomadas nesta reflexão partem da Sociologia de Durkheim e seguem pela via da Psicologia Social desenvolvida por Moscovici.

A teoria social oferece um conjunto de possibilidades do ponto de vista teórico-metodológico que pode suscitar a reflexão, e o debate, bem como

\footnotetext{
${ }^{1}$ Versão preliminar de palestra apresentada no IV Interprogramas da COMPÓS, Brasília de 28 a 29/10/2004.
} 
inspirar os pesquisadores a enfrentar as novas questões contemporâneas sem que os fenômenos sejam reduzidos a uma visão simplista. Poderíamos citar inúmeros exemplos de como conceitos cunhados nas Ciências Sociais nortearam as análises e são utilizados até hoje nas Ciências da Comunicação, como é o caso da noção de indústria cultural, elaborado pelos teóricos frankfurtianos. Por outro lado, as interfaces das teorias sociais com o campo comunicacional podem aprofundar outras dimensões dos processos comunicacionais, importantes na produção cultural, e dessa forma colaborar com a constituição de novas teorias sociais.

\section{TEORIA SOCIAL E COMUNICAÇÃO: AS REPRESENTAÇÕES SOCIAIS}

Tomo como marco para reflexão a passagem do modo de produção feudal para o capitalista e os problemas que nasceram com a mudança das sociedades agrárias para sociedades industriais e urbanas e as diferentes repercussões que trouxeram essas mudanças no plano econômico, político, social e cultural na sociedade ocidental. Nos séculos XVIII e XIX, contextos em que surgem, proliferam e se fortalecem as teorias sociais, tendo modelo o paradigma da Sociologia, ciência emergente da época, cujos métodos buscavam pesquisar as causas dos fenômenos com a finalidade de explicar e compreender os fenômenos sociais advindos das transformações, introduzidas pelo novo modo de produção capitalista e o desmoronamento da sociedade feudal. Nessa configuração social, os intelectuais elaboram as teorias sociais explicativas para as novas questões provocadas por essas transformações entre as quais a relação entre a sociedade e a comunicação. Entretanto as questões e os problemas da relação entre a sociedade e a comunicação tornam-se mais visíveis e complexos a partir do século XX, quando os meios de comunicação de massa adquirem no mundo social maior espaço, passando a ocupar uma centralidade na vida social e cultural.

\footnotetext{
${ }^{2}$ Doutor em Sociologia pela USP. Professor adjunto do Departamento de Ciências da Informação e do Programa de Pós-graduação em Comunicação e Informação da UFRĢ̨S.
} 
No século XIX, a teoria social clássica estava preocupada com a formação de uma moral única para a sociedade, inspirada no positivismo de Comte, a ciência, através do espírito cientifico, seria a nova religião da humanidade. Assim, a nova moral da sociedade era constituída com base nos princípios da razão humana, objetivos e laicos. Nesse processo, o papel das instituições, principalmente aquelas ligadas à produção do conhecimento e da elaboração das concepções de mundo, possuía um papel fundamental. O próprio marxismo como vertente interpretativa como um todo, contrapondo a filosofia e a teoria positivista, mas com outros pressupostos, metodologias e categorias analíticas, se constituiu em uma teoria social gerada com intuito de dar visão totalizadora que abarcasse e explicasse os diversos fenômenos que compõem as formas de representar a realidade social.

No século XX, a intensificação da especialização do próprio conhecimento cientifico e a conseqüente constituição de novas áreas do conhecimento, bem como os avanços das tecnologias fizeram com que diferentes vertentes teóricas emergissem e proliferassem na sociedade, porém sem a preocupação com a formação de uma "moral” ou pensamento “único" para explicar a complexidade da vida em sociedade. Hoje as preocupações estão centradas em questões que dizem respeito à produção dos consensos. Mas como o consenso é possível em uma sociedade diversa, plural e global ao mesmo tempo? Se existe uma multiplicidade de formas de pensamento e formas de representá-lo? Os meios de comunicação, nesse contexto, assumiram um papel que ultrapassa a de condição meros veículos das mensagens e dos conteúdos. Além de veicularem informações aos cidadãos eles, no processo da comunicabilidade da cultura e seus valores, são responsáveis pela produção dos sentidos que circulam na sociedade. Isso nos remete à teoria das representações sociais.

Nas Ciências Sociais a idéia de representação social parte do conceito de representações coletivas, de Emile Durkheim (1975). O autor utilizava os adjetivos "social" e "coletivo" indistintamente, pois na sua concepção eles tinham a mesma significação. Ao se referir às representações coletivas o autor as definiu como as formas de conhecimento, do senso comum ao pensamento científico, ou as idéias produzidas socialmente e que não podem ser explicadas 
como fenômenos da vida individual, tampouco podem ser explicados pelos fenômenos psicológicos. As representações coletivas são as formas de pensamento que a sociedade elabora para expressar sua realidade. Essas formas são incorporadas e interiorizadas pelos indivíduos através da vida em sociedade através das normas, das regras que formam a estrutura social. Como essas formas de pensamento não são universais nem são dadas às consciências $\grave{a}$ priori formam-se os sistemas de representação coletivos nos quais torna-se possível criar esquemas de percepção, juízos que fundamentam as maneiras sociais de agir, pensar e sentir dos indivíduos.

Durkheim estudou as representações coletivas nas sociedades primitivas através das crenças em seus estudos sobre religião. Nessa abordagem, as crenças, solidificadas nas tradições culturais, instituições sociais fixas e no cultivo de mitos entre os grupos tribais eram responsáveis por constituição de sociedades mais sedimentadas. Em seus estudos o autor enfatizou uma concepção estática das representações coletivas, mostrando que as idéias permanecem na vida social como "[. . .]camadas de um ar estagnado na atmosfera da sociedade".(MOSCOVICI, 2003, p.47), diferentemente da abordagem de Moscovici, que tratou as representações sociais na sua dinamicidade, pois estava preocupado com a estrutura e a dinâmica das representações sociais.

Nos contextos das sociedades industriais e das pós-industriais, as representações sociais assumem um caráter móvel, plástico e circulante. Ao mesmo tempo em que elas surgem, podem desaparecer. Em diversos campos (político, religioso, científico, entre outros), muitas delas não conseguem sequer se sedimentar, pois o seu tempo de duração (existência) não as deixa se transformarem em tradições imutáveis, o que mostra o seu caráter altamente dinâmico. Conforme afirma Moscovici (2003, p.48):

A sua importância continua a crescer, em proporção direta com a heterogeneidade e a flutuação dos sistemas unificadores - as ciências, religiões e ideologias oficiais - e com as mudanças que elas devem sofrer para penetrar na vida cotidiana e se torna parte da realidade comum. Os meios de comunicação de massa aceleram essa tendência, multiplicam tais mudanças e aumentam a necessidade de elo entre, de uma parte, nossas ciências e crenças gerais puramente abstratas e, de outra parte, nossas atividades concretas como indivíduos sociais. Em outras palavras, existe $\mathrm{uma}$ necessidade contínua de 4 re-constituir o 'senso comum' ou a 
forma de compreensão que cria o substrato das imagens e sentidos, sem a qual nenhuma sociedade pode operar. Do mesmo modo, as coletividades hoje não poderiam funcionar se não criassem representações sociais baseadas no tronco das teorias e ideologias que elas transformam em realidades compartilhadas, relacionadas com as interações entre pessoas que, então, passam a constituir uma categoria de fenômenos à parte.

Conforme frisa o autor (p.49) as representações sociais são “[. . .] fenômenos específicos que estão relacionados com um modo particular de compreender e de se comunicar - um modo que cria tanto realidade quanto senso comum."

Nesse sentido, os meios de comunicação de massa se colocam como u m componente cultural importante na teoria das representações sociais. Nos estudos das representações sociais nos meios de comunicação geralmente se inclui a análise de conteúdo das coberturas que a mídia realiza a respeito dos temas que trata, pois as representações sociais se encontram tanto nas mentes das pessoas quanto nos meios, sendo necessário interceptá-las, exemplifica-las e analisá-las em ambos lugares. (FARR, 2003).

No mundo globalizado, vivemos sob uma avalanche de informações, dos discursos, dos pacotes cinematográficos, das telenovelas, dos telejornais, dos programas de auditório, dos realty shows e dos “desenhos animados” entre outros produtos midiáticos que, saturados de imagens, tornam os objetos, os acontecimentos e as pessoas in-significantes. A produção de realidade, sob forma de inflação e de banalização dos sentidos, coloca as idéias e as formas de pensamentos que circulam no espaço público no mesmo patamar das mercadorias produzidas em série que devem ser consumidas na mesma velocidade em que são produzidas.

Assim, como afirma Ferreira (2003, p.19) “[. . . ]a realidade é substituída e dissuadida pela proliferação do sentido, acedendo deste modo a um estatuto de pretexto de uma nova realidade, de uma realidade de natureza discursiva e imagética." Entretanto, conforme explica a autora, isso não ocorre pelo processo de espetacularização da realidade, mas porque neutraliza a oposição entre a realidade e os seus simulacros mediáticos, tornando todos e tudo banal. 
Com o delinear da sociedade pós-moderna e com ela a hiperfragmentação do mundo e dos indivíduos, faz com que se estabeleçam várias e diferentes éticas e moralidades que atuam concomitantemente no mundo social. Nesse contexto de pulverização dos sentidos, uma moral baseada no individualismo do sujeito torna cada vez mais difícil o estabelecimento de uma "moral única" na sociedade. Conseqüentemente, há uma maior dificuldade dos indivíduos se agregarem em torno de projetos sociais comuns, criarem utopias, formarem identidades sólidas ou firmarem posições políticas em torno das mesmas questões.

A compreensão de que o fato social não existe como dado, mas como construção midiática, é que define o fenômeno da midiatização (VERÓN, 1997). A redução da realidade a um discurso formatado, produzido para ser veiculado em mídias de grande alcance, produz uma simplificação e banalização do "real”.

\section{COMUNICAÇÃo E MIDIATIZAÇÃo}

A midiatização é um fenômeno complexo constituído e constitutivo de u m conjunto de interações sociais e discursivas. Ela representa a instância das relações sociais à medida que transforma a ordem da vida cotidiana, criando novos valores, novas formas de interação que constituem as práticas sociais, culturais e as formas de exercícios do poder. As representações sociais disseminadas pelos meios de comunicação passam a se constituírem realidades as quais passam a integrar o perfil da opinião pública em forma de discurso da atualidade, tornando parte do senso-comum. As influências sociais da comunicação no processo das representações sociais servem como meio para estabelecer ligações e conexões significativas com as quais nos relacionamos e interagimos uns com os outros.

Entretanto, o discurso da atualidade manifesta o caráter ambíguo da comunicação midiatizada que se constitui em um discurso polifônico, acolhendo e mediando todos os campos do conhecimento, exercendo um poder hegemônico, pois sua enunciação deriva do campo socialmente legitimado. 
Dependendo do tipo de mediação processada, esse espaço público, inicialmente plural e democrático, pode provocar, segundo Rodrigues, (1997, p.41) u m esvaziamento da sociabilidade: “[. . .] transforma-se em espaço de circulação anônima, repercutindo do nível da privacidade uma pura forma perversa e esquizóide de visibilidade social, espécie de miragem espectacular de todas as modalidades de convivência”.

Nesse sentido, a midiatização representa um posto avançado de observação e de construção dos sentidos. Ela é uma interação social complexa entre diversos campos. Nesse processo, a mediação é resultante da articulação entre os dispositivos tecnológicos e das condições específicas da produção de sentido. A midiatização é uma fala intermediária a tantas outras, mas com poder de articulação e enquadramento das demais. Ela as administra e fomenta a partir dos seus pressupostos ideológicos e culturais. Deste modo, evidencia-se o discurso midiático como sendo um produtor de sentidos a partir de outros discursos produzidos socialmente. Entretanto, sua força consiste no caráter persuasivo em dar visualidade aos acontecimentos e às interpretações, possibilitando o acesso relativamente plural às mensagens e à produção de sentido social.

Para elucidar melhor esse processo, apresenta-se o modelo da Semiose da Midiatização (Figura 1) pensado por Verón (1997, p. 9), que servirá de apoio para compreender a interação mídia-instituições-indivíduos, enfatizando o papel do discurso midiático na produção dos sentidos.

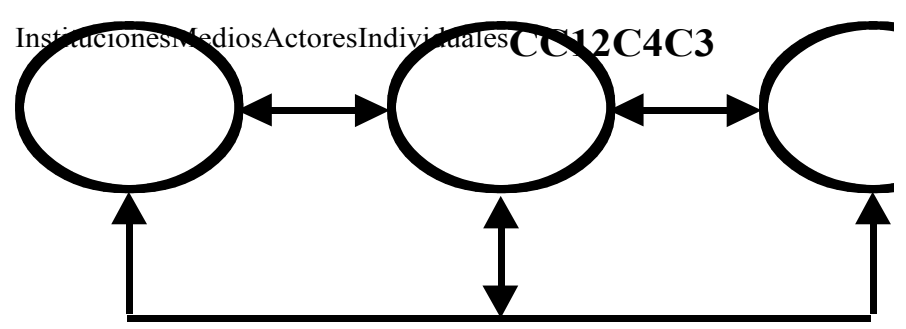

Este esquema permite visualizar a dinâmica de funcionamento dos meios de comunicação e a sua interação com outras instituições sociais. Os 
meios são instituições diferenciadas pelo lugar central que ocupam na atualidade e pelo papel que exercem na mediação e na midiatização das informações de interesse social. Participam desse processo os atores individuais, cidadãos pertencentes à sociedade, inseridos nas complexas interações sociais. Os "Cs" ligados às duplas flechas significam os coletivos que se formam no processo de comunicação.

Segundo o esquema, a semiose da midiatização apresenta, no mínimo, quatro zonas que produzem coletivos: a) a relação dos meios com as instituições sociais; b) a relação dos meios com os atores individuais; c) a relação das instituições com os atores e a maneira pela qual os meios afetam essa relação; e, d) a maneira como as instituições afetam umas as outras.

O fenômeno da midiatização é composto por mensagens, com significação social, que circulam como produtos em um mercado pluridiscursivo. Como afirma Rodrigues (1997, p.162), “[. . . ]o campo dos media torna-se hoje o meio obrigatório de publicidade e da conseqüente geração de efeito de realidade.” Desse modo, integra os múltiplos campos sociais que ele toma como referência para produção do discurso da atualidade.

O processo de midiatização não pode ser compreendido através de uma configuração polarizada entre campos sociais - campo midiático - mas como u m fenômeno decorrente de múltiplas, complexas e plurais interações. A mediação e o movimento dos sentidos proporcionados pelos constantes envios e reenvios de informações provocam profundas tensões e a necessidade de efetivas negociações entre os campos e atores sociais envolvidos.

Cada campo social possui suas normas próprias - contratos - para seus discursos, que permitem ao seu público uma compreensão das mensagens. Embora os múltiplos discursos das diversas instituições sociais, formam linguagens técnicas nem sempre acessíveis e decodificáveis pelos atores sociais. O campo midiático possui regras específicas, que rompem a ordem do campo de origem, para a efetivação de uma nova ordem assimilada pela pluralidade da opinião pública. Ela possibilita uma leitura dos acontecimentos sociais, dando coerência e clareza, tornando-os visíveis em espaço e tempo limitados, graças à velocidade da tecnologia, porém o faz de acordo com sua ótica. 
Nesse cenário de banalização da essência humana decorrente, da simplificação do cotidiano socializado pela mídia, aquilo que se destaca do "real” é apenas uma superfície, um simulacro. (LANDOWSKI, 1992). A ordem da atualidade, via da tecnicidade, é o consumo quantitativo das informações em alta velocidade, sem profundidade, ignorando a singularidade dos diferentes campos e atores sociais envolvidos.

Portanto, a midiatização é um processo no qual o "real" se produz sociotecnicamente e, através dele, se tem acesso à experiência da vida cotidiana, em forma de representação do mundo que se sujeita a lógica do mundo midiático e a sua espetacularização. Entre os dois reais, o virtual e o de referência, existe sempre uma lente que ora aumenta ora reduz o foco. Através dessa lente, contagiada pela visão de mundo do veículo, é que os campos e os atores sociais têm acesso às informações sobre a realidade social.

Entretanto, esse agendamento midiático não impossibilita possíveis interpretações dos sujeitos. No processo de decodificação das mensagens e criação de sentidos existem mais brechas do que se pode imaginar. Nesse sentido, Certeau (1994) contraria a concepção de que as instituições determinam os papéis sociais e as relações que estabelecem entre os sujeitos através dos seus discursos que sucumbe com a idéia de liberdade de invenção dos sujeitos no processo de construção e criação dos sentidos. Assim, o autor reforça a idéia das apropriações do cotidiano, pactos de leitura e resignificações dos sentidos em função da experiência pessoal e da interação social. Nessa perspectiva, a noção de “invenção" associa-se aos modos de perceber, representar, ver, ler, ouvir e sentir dos sujeitos, rompendo com a lógica do sentido dado e determinado.

Assim, o "real", socialmente produzido pela mídia é produto de uma série de interações e movimentos de sentidos. Ele é perpassado por diversos estilos, estéticas, discursos e culturas de diferentes campos de origem. Assim, no processo de construção e reconstrução, o acontecimento é submetido a um tratamento técnico-estético até atingir o modelo socialmente consumido na atualidade.

Como afirma Lopes (2003), o campo da comunicação é o resultado de u m 
“contrato" múltiplo que mobiliza o entorno social e os diversos sujeitos que dele participam. A representação dessa relação contratual determina os seus usos, as aplicações teóricas e estabelece os limites e raios de sua ação. O contrato também define a sua hermenêutica e a epistemologia da produção do seu conhecimento. Conforme o autor ( p.168):

Considerando as diferentes condições sociais, dir-se-ia que os contratos de comunicação são múltiplos e celebráveis nos momentos em que há o encontro entre parceiros. Imagina-se que eles existem de fato ou estão em processo de montagem, a partir do exame dos atos e situações comunicacionais que neles circulam. Seus elementos mais essenciais são o comportamento social, as manifestações discursivas e o sistema de crenças dominantes em cada época.

$\mathrm{Na}$ contemporaneidade, as tecnologias de informação e comunicação, através de suas linguagens, facilitam a construção de "eus" "midiatizados" e a constituição de indivíduos formados por morais "próprias", posturas individuais e autônomas. Os blogs, webblogs na Internet, por exemplo, criam a necessidade nos indivíduos de exporem o seu "ego" publicamente. De certa forma, essas interações mediadas pelas tecnologias agregam algum valor coletivo, mesmo que sejam valores “próprios", morais parciais que compõem uma ética individualista. Nesse processo, o estudo das representações sociais são elementos importantes para desvendar a constituição de diferentes tipos de moral.

\section{CONSIDERAÇÕES FINAIS}

Repensar a própria prática e revê-la a partir das representações sociais, sob as quais se justificam práticas hegemônicas, é discutir sobre a necessidade de uma ética que norteie a produção de sentidos das produções midiáticas. Longe de ser uma ética universalista, ela é pluralista em respeito ao multiculturalismo emancipatório, fundamentado em princípios de solidariedade, justiça social, fraternidade e emancipação humana. Ainda que isso necessite ser ressignificado continuamente no interior de cada 
cultura, ela se torna capaz de contrapor as formas de massificação das representações que circulam na esfera pública com intuito de formar um pensamento único.

As representações sociais estão assentadas em valores e princípios morais nos quais a sociedade, os grupos e os indivíduos se guiam para construir e reconstruírem os sentidos de suas ações. Diante dos conflitos e das tensões que vivemos na atualidade, da "crise de valores" e da fragmentação do mundo, os meios de comunicação seriam responsáveis, junto com os movimentos sociais e a sociedade civil, pela formulação de uma nova política e moral públicas. Nesse processo, os meios de comunicação na mediação e veiculação de informações (emancipatórias) ligadas ao direito à diferença e a diversidade cultural, associados aos movimentos ambientalistas, podem criar e recriar novas representações sociais capazes de mobilizar a vontade coletiva.

A constituição de uma nova moral na esfera pública passa pelo repensar das consciências individuais, pelas novas simbolizações e percepções que circulam nessa esfera. As mudanças nas formas perceptivas das relações cotidianas podem levar a mudanças significativas no plano das concepções sobre o mundo e as suas relações. O multiculturalismo seria um movimento capaz de estabelecer uma nova moral pública?

A Teoria das Representações Sociais contribui com os estudos da Comunicação à medida que, a partir dela, podem ser estabelecidos os elos e os nexos entre as partes isoladas com o conjunto da sociedade. Isso ocorre quando ela mostrar de que modo as representações sociais são organizadas pelos meios na construção de produtos midiáticos e como a cultura dos meios produz o senso comum, participando da construção da cultura geral. Portanto, a teoria social pode fornecer mapeamentos que nos permitem visualizar o modo como a sociedade organiza e dissemina as formas de pensamento. Assim, através do modo como a mídia combina e utiliza as suas estratégias de comunicação, podemos desvendar e compreender como se formam as estruturas, os processos internos e as dinâmicas da lógica da produção e criação dos sentidos que dão sustentação a determinadas formas de conceber o mundo, às instituições, seus discursos e suas práticas, e, finalmente interferem nos modos de interagir 
socialmente.

A interface da teoria das representações sociais com a comunicação não decorre apenas do seu efeito multiplicador que opera como um instrumento cultural nas mediações do processo das identidades culturais, da sociabilidade, da memória social e das práticas políticas, sociais e culturais. As representações sociais são elementos fundamentais no processo de produção de sentidos, pois a partir delas se definem e instituem as formas de percepção, as ações e as práticas, os métodos e, inclusive, a constituição dos objetos sobre os quais se inscreve determinado campo do conhecimento.

\section{REFERÊNCIAS}

ARBEX, J. J Uma outra Comunicação é Possível In: MORAES, Dênis de. (org.). Por uma outra Comunicação: mídia, mundialização cultural e poder. Rio de Janeiro: Record, 2003. p.385-400

ARON, Raymond. As Etapas do Pensamento Sociológico. 4.ed. São Paulo: Martins Fontes, 1993

BATESON, Gregory. Comunicação. In: WINKIN, Yves (Org.). La Nueva Comunicación. Barcelona: Kairós, 1994· p.120-50

BRAGA, J.L.W.J.G. Constituição do Campo da Comunicação In: Anais do 9. Encontro Nacional da Compós. Porto Alegre: PUC/RS, 2000. BOURDIEU, Pierre. O Poder Simbólico. Lisboa: Difel, 1989. CEBALLOS, Maritza. Y ALBA, Gabriel. Viaje por el concepto de representación. Signo y Pensamiento 43, Facultad de Comunicación y Lenguaje, Pontificia Universidad Javeriana, Colombia. Vol.22, julio/diciembre,2003. p.11-21 CERTEAU, Michel de. A Invenção do Cotidiano I. Petrópolis: Vozes, 1994.

CORREIA, João. O Poder do Jornalismo e a Mediatização do Espaço Público. Revista da Comunicação e Linguagens, Lisboa: Relógio D’água, 2000. p.193-209 
DURKHEIM, Emile. Representações Individuais e Representações Coletivas. Filosofia e Sociologia. 2.ed. Rio de Janeiro : Forense Universitária, 1975. p.15-49

FARR, Robert M. De las representaciones colectivas a las representaciones socials: ida e vuelta. In: CASTORINA, José Antonio (org). Representaciones Sociales: problemas teóricos y conocimentos infantiles. Barcelona: Gedis editorial, 2003. p.153-175

FERREIRA, Naura S. C. É possível humanizar a formação no mundo globalizado? Sim, é possível. In: A Gestão da Educação na Sociedade Mundializada: por uma nova cidadania. Rio de Janeiro: DP\&A, 2003. p. 1530

LANDOWSKI, Eric. A Sociedade Refletida. São Paulo: Educ, 1992.

LOPES, Luís Carlos. Hermenêutica, teorias da representação e da argumentação no campo da comunicação. In: LOPES, Maria Immacolata Vassalo de. (org. ). Epistemologia da Comunicação. São Paulo: Loyola, 2003. p.163-185

MANTİN-BARBERO, J. Os Métodos: dos meios às mediações. In: Dos Meios às Mediações: comunicação, cultura e hegemonia. Rio de Janeiro: UFRJ, 1997. p.258-308.

MOSCOVICI, Serge e MARKOVÁ, Ivana. La presentación de las representaciones sociales: diálogo con Serge Moscovici: In: CASTORINA, José Antonio (org). Representaciones Sociales: problemas teóricos y conocimentos infantiles. Barcelona: Gedis editorial, 2003. p. 111-152

PAVARINO, Rosana Nantes. Teoria das Representações Sociais: Pertinência para as pesquisas em Comunicação de massa. XXVI Congresso 
Brasileiro de Ciências da Comunicação- INTERCOM, Belo Horizonte/ MG 2 a 6 set, 2003. NP Teorias da Comunicação.

RODRIGUES, Adriano Duarte. Estratégias da Comunicação. Lisboa: Presença, 1997.

VERÓN, E. Esquema para el Análisis de la Mediatización. Revista Diálogos de la Comunicación, Lima, n. 48, p.9 out. 1997. 